\title{
Indoor exposure to airborne PAHs: A comparison of stir bar sorptive extraction and pump sampling
}

\author{
Roland Becker ${ }^{1}$, Lisa Heyn ${ }^{2}$, and Christian Jung ${ }^{1}$ \\ ${ }^{1}$ Bundesanstalt fur Materialforschung und -prufung \\ ${ }^{2}$ Hochschule fur Technik und Wirtschaft Berlin
}

January 14, 2021

\begin{abstract}
Stir bar sorptive extraction (SBSE) was compared with standardized pump sampling regarding the prospects to assess airborne levels of polycyclic aromatic hydrocarbons (PAHs) in indoor environments. A historic railway water tower, which will be preserved aa technical monument for museum purposes, was sampled with both approaches because built-in insulation material was suspected to release PAHs to the indoor air. The 16 PAH on the US EPA list were quantified using gas chromatography with mass selection detection in filters from pump sampling after solvent extraction and on SBSE devices after thermal desorption. SBSE was seen to sample detectable PAH masses with excellent repeatability and a congener pattern largely similar to that observed with pump sampling. Congener patterns were however significantly different from that in the PAH source because release from the insulation material is largely triggered by the respective congener vapor pressures. Absolute masses in the ng range sampled by SBSE corresponded to airborne concentrations in the ng L - 1 range determined by pump sampling. Principle differences between SBSE and pump sampling as well as prospects of SBSE as cost-effective and versatile complement of pump sampling are discussed.
\end{abstract}

Indoor exposure to airborne PAHs: A comparison of stir bar sorptive extraction and pump sampling

Roland Becker ${ }^{a, *}$, Lisa $\operatorname{Heyn}^{b}$, Christian Jung ${ }^{a}$

${ }^{a}$ Bundesanstalt für Materialforschung und-prüfung (BAM), Berlin, Germany

${ }^{b}$ Hochschule für Technik und Wirtschaft (HTW); Berlin, Germany

\section{Abstract}

Stir bar sorptive extraction (SBSE) was compared with standardized pump sampling regarding the prospects to assess airborne levels of polycyclic aromatic hydrocarbons (PAHs) in indoor environments. A historic railway water tower, which will be preserved a technical monument for museum purposes, was sampled with both approaches because built-in insulation material was suspected to release PAHs to the indoor air. The $16 \mathrm{PAH}$ on the US EPA list were quantified using gas chromatography with mass selection detection in filters from pump sampling after solvent extraction and on SBSE devices after thermal desorption. SBSE was seen to sample detectable PAH masses with excellent repeatability and a congener pattern largely similar to that observed with pump sampling. Congener patterns were however significantly different from that in the PAH source because release from the insulation material is largely triggered by the respective congener vapor pressures. Absolute masses in the ng range sampled by SBSE corresponded to airborne concentrations in the $n g \mathrm{~L}^{-1}$ range determined by pump sampling. Principle differences between SBSE and pump sampling as well as prospects of SBSE as cost-effective and versatile complement of pump sampling are discussed.

Keywords: PAH, adsorption, sampling, stir bar, extraction, GC-MS 
Correspondence to: Roland Becker

roland.becker@bam.de

\section{Introduction}

The permissible concentration of harmful substances such as polycyclic aromatic hydrocarbons (PAH) in indoor air is regulated ${ }^{1,2}$. Obvious sources for such compounds are normally tackled by insulation, a ventilation regime or are removed altogether. In the context of displaying industrial heritage to the public in a museum setting there is reason to retain technical installations in their original form. This can lead to contaminant sources that require careful handling in compliance with the regulation in place. In the concrete case a water tower constructed in 1904 near Berlin, Germany, and operated until 1987 for boiler feedwater supply for steam trains is being conserved in the found condition as industrial monument with the aim to admit visitors. During operation of the tower water was pumped through steel pipes from a well under the tower into the reservoir above the third floor. Pipelines and fittings were insulated with jute fabric and cardboard soaked with a bituminous material. Consequently, the insulation material contains $\mathrm{PAH}$ in considerable amounts which leads inevitably to the release of PAH to the indoor air. Therefore, the PAH concentration in the air is relevant to manage the admission of museum visitors. Indoor concentrations of naphthalene and benzo $\left[a\right.$ ]pyrene are regulated and should not exceed $10 \mathrm{mg} \mathrm{m}^{-3}$ and $1 \mathrm{ng} \mathrm{m}^{-3}$, respectively ${ }^{1,2}$. A number of procedural variants most based on pump sampling for the determination of airborne PAH levels have been reported ${ }^{3}$. Usually, concentration levels are determined following the pump sampling procedure laid down in ISO $16000-12^{4}$.

No visitors other than technical staff were admitted to the water tower during the restoration period. The third floor below the water reservoir tank, which is called "Tropfboden" (literally: "drip floor", due to dripping of condensed moisture), was chosen as a point of central museum interest, because of the tank and its special distribution of pipelines. According to the safety habits of the time of construction, the drip floor is accessed via an exceptionally steep, long steel ladder. As a result, the transport of the pump sampling equipment was impeded. This situation was used to explore a rapid and easily applicable passive sampling approach regarding its proficiency as a complement to pump sampling. A straight-forward option for facile sampling is stir bar sportive extraction (SBSE) that is based on exposure of coated magnetic bars to environmental compartments and has been used over than 20 years for a variety of analytes ${ }^{5}$. While the focus has been on extraction from aqueous phases stir bar extraction from open air has been reported for phosphorous flame retardants ${ }^{6}$ and as headspace SBSE for determination of volatiles form food ${ }^{7,8}$ and in forensic applications ${ }^{9,10}$. Regarding PAH so far nearly exclusively application of SBSE for trace concentration determinations in water has been reported ${ }^{11,12,13,14,15,16,17,18}$. Meanwhile, the use SBSE for the assessing the effect of coal combustion on indoor airborne PAH levels was reported ${ }^{19}$. SBSE displays straight forward and easy application as devices may be exposed for different periods of time, easily transported after collection, stored over prolonged periods of time and analysed under repeatability conditions. Thus, a proof of concept study was performed to explore SBSE as tool to provide a rapid estimate of PAH concentration levels in order to assess the significance for more complex standardized sampling procedures.

\section{Experimental}

\subsection{Chemicals and materials}

PAH calibrants were prepared from NIST SRM 1647f (16 EPA PAH in acetonitrile) purchased from Promochem (Wesel, Germany). Cyclohexane and diethyl ether were picograde and obtained from Promochem. Surrogate standard mixture PAH-Mix 9 was from Dr. Ehrestorfer (Augsburg, Germany) and contained the deuterated 16 EPA-PAH in cyclohexane. Stir bar sorptive extraction (SBSE) devices (polydimethylsiloxane, $10 \mathrm{~mm} \times 0.5 \mathrm{~mm}$ ) were obtained from Gerstel (Mülheim an der Ruhr, Germany). Orbo-1000 polyurethane foam (PU foam) cartridges (22 mm outer [?] x $7.6 \mathrm{~cm}$ ) containing $0.022 \mathrm{~g}$ PU foam $\mathrm{cm}^{-3}$ and matching quartz filters (3.5 mm [?]) were purchased from (Supleco, Mainz, Germany) and received in amber glass bottles. 


\subsection{Sampling with stir bar sorptive extraction}

SBSE devices were cleaned in a TDU C200 conditioner (Gerstel) at $300 \operatorname{deg}$ C under a nitrogen flow of 100 $\mathrm{mL} \mathrm{min}^{-1}$ for two hours and kept in closed chromatography glass vials containing inserts with metal springs (Gerstel) until application on the sampling spots. For sampling, the devices were positioned on specific sites of the steel construction and the wall. In order to avoid direct contact with the wall or steel tubes aluminum foil were placed between the magnetic SBSE devices and the steel part. For sampling of the cross section of the room a tape was fixed on the ground and SBSE devices were placed on top of it as outlined in Fig. 1. Room temperature and air humidity were monitored using a VoltCraft DL-121 TH Multidata Logger. After the respective exposition time, SBSE devices were collected and put into the vials for transport to the laboratory and stored until analysis under repeatability conditions on the last day of each sampling campaign.

\subsection{Pump sampling}

Indoor air was collected with a Gasprobenehmer GS312 pump sampler (Desaga, Heidelberg, Germany) equipped with a flowmeter from Kirchner GmbH (Hamburg, Germany). the PU foam cartridges each with a quartz filter mounted on top were placed $1 \mathrm{~m}$ above ground level and connected with a polyethylene hose to the pump sampler. Air was sucked through the filter at a flow of $10 \mathrm{~L} \mathrm{~min}{ }^{-1}$ until a total volume of $1 \mathrm{~m}^{3}$ was reached. Thereafter, the pump was turned off and the filter was dismantled and stored in the original amber glass bottles until analysis in the laboratory on the same day. Each quartz filter was dismantled and the cartridge was spiked with $20 \mu \mathrm{L}$ of the surrogate standard solution in toluene (1:10) and submitted to pressurized fluid extraction on a ASE-350 instrument (Thermo Scientific, Karlsruhe, Germany) using a $22 \mathrm{~mL}$ cell equipped with an ASE extraction cellulose filters on the bottom (Thermo Scientific). The cells were heated to $100{ }^{\circ} \mathrm{C}$ for 10 min (static extraction) and cyclohexane/diethyl ether (95:5, v:v) was used as extraction solvent at 140 bar. The flush volume was $60 \%$. Extracts were collected in $60 \mathrm{~mL}$ glass vials and concentrated to $1 \mathrm{~mL}$ under a stream of nitrogen and transferred to a GC vial. Each quartz filter was spiked and extracted in the same manner.

\subsection{Quantification of PAH using GC-MS}

PAH congener quantifications were performed on an Agilent 7890A gas chromatograph (Agilent Technologies, Waldbronn, Germany) equipped with a MPS2 autosampler including an automated tube exchange device (Gerstel, Mülheim/Ruhr, Germany), a Gerstel thermal desorption unit (TDU) including a TDU tray, a Gerstel CIS4 cold injection system, and a Select PAH column $(30 \mathrm{~m}$ x $0.25 \mathrm{~mm} 0.15 \mu \mathrm{m})$ from Agilent. The gas chromatograph was coupled to an Agilent 5975C inert XL mass selective detector. The TDU was run in the splitless mode and started at $30{ }^{\circ} \mathrm{C}$ (held for $1 \mathrm{~min}$ ) and was ramped with $12{ }^{\circ} \mathrm{C} \mathrm{min}{ }^{-1}$ to $300{ }^{\circ} \mathrm{C}$. The TDU transfer temperature was kept at $320{ }^{\circ} \mathrm{C}$. The CIS4 was operated in the solvent vent mode at $8.77 \mathrm{psi}$ and a helium (5.0) vent flow of $60 \mathrm{~mL} \mathrm{~min}{ }^{-1}$. The GC oven program started at $70{ }^{\circ} \mathrm{C}$ (held for 1 min) and was ramped with $40{ }^{\circ} \mathrm{C} \min ^{-1}$ to $140{ }^{\circ} \mathrm{C}$, then ramped with $20{ }^{\circ} \mathrm{C} \min ^{-1}$ to $350{ }^{\circ} \mathrm{C}$ and held for $5 \mathrm{~min}$. Helium 5.0 was used as carrier gas with a constant flow of $1.0 \mathrm{~mL} \mathrm{~min}{ }^{-1}$. The CIS injector was run in the splitless mode, the transfer line, the ion source, and the quadrupole were kept at $280{ }^{\circ} \mathrm{C}, 230{ }^{\circ} \mathrm{C}$, and $150{ }^{\circ} \mathrm{C}$, respectively. The detector was run in the single ion monitoring mode (electron impact, $70 \mathrm{eV}$ ) using the fragments and retention time windows listed in supplementary Table S1. For calibration of PAH determinations in extracts from PU foams, quartz filters, and PAH source material fourteen gravimetrically prepared dilutions of NIST 1647f in toluene were injected via the CIS4 injector into of the GC-MS system similar as likewise the processed extracts (section 2.3). For details on the concentrations and the calibration curves obtained by linear regression throughout with coefficients of determination $>0.995$ see supplementary Table S1. For calibration of the SBSE analyses seven cleaned SBSE devices were spiked with toluene solutions of NIST $1647 \mathrm{f}$ and submitted to the TDU via the tube exchange device similar to the SBSE devices exposed for airborne PAH sampling (supplementary Table S1).

\subsection{Quality control/quality assurance}

Utmost care was taken to avoid contamination of sampling devices (stir bars and PU foams) with PAHs. 
Blank runs were performed on cleaned SBSE devices and pristine PU foam items and revealed PAH contents below detection limits. Each sampling point in time and space was performed in triplicate after preliminary SBSE runs had been performed to assess suitable exposure periods. Transport of SBSE devices and sampling filters from the sampling site to the laboratory was done with utmost care to avoid contamination with PAHs. $\mathrm{PAH}$ recovery rates from the polyurethane foam was determined by extraction of PU foam cartridges fortified with solutions the 16 EPA PAH in toluene prepared from SRM NIST SRM 1647f (1:10). After evaporation of the solvent the cartridges were submitted to pressurized fluid extraction as described in section 2.4 either directly or after having rested for one to ensure compete solvent evaporation. Peak areas for each PAH as determined form the extracts and a solution of NIST SRM $1647 \mathrm{f}$ diluted in the extraction solvent to simulate a 100\% recovery were compared (see supplementary Table S2). Linearity of the PAH recovery from the SBSE devices over the relevant range was investigated by spiking cleaned devices with $1 \mu \mathrm{L}$ of solutions of NIST SRM $1647 \mathrm{f}$ diluted in toluene. The solvent was allowed to evaporate at ambient temperature and after $1 \mathrm{~h}$ the SBSE device were submitted to thermal desorptive extraction as described in section 2.4. For amounts of substances spiked and coefficients of determination see supplementary Table S3. Limits of detection and quantification were determined by the linear regression method laid down in ISO $11843^{20}$ and implemented in the software package DINTEST ${ }^{21}$ and it could be shown to reach at least between 0.26 and $3.4 \mathrm{pg}$ absolute per device depending on the PAH congener, for details see supplementary Table S3. In order to estimate the sorption capacity of PAHs a number of SBSE devices was incubated in the headspace of charcoal. It was seen that all $16 \mathrm{PAH}$ congener were adsorbed to an extent far beyond the concentration range observed in this work (data not shown).

\section{Results and discussion}

\subsection{Building structure and sampling regime}

Fig. 1 depicts the spatial situation on the third floor below the water reservoir (drip floor) from which the boiler feed water was dispensed to railway steam engines. The circular room exhibits staircases from the second floor and to the fourth floor containing the reservoir tank for the water supply.

Figure 1: Layout of the third floor, PAH sources and sampling spots.

This building displays a complex air flow situation and was designed for a constant air exchange with the outside via an open lantern. The air exchange rate is unknown to its extend and within the building there was never any sensing of air movement by the authors. The maximum indoor temperature on the drip floor follows largely the outside temperature and ranged in 2019 between $5{ }^{\circ} \mathrm{C}$ in January and $30{ }^{\circ} \mathrm{C}$ in early July. It was decided to measure the airborne PAH concentration near the wall (Fig. 1, position P) as this would be the area basically used by museum visitors.

The PAH source is the original jute fabric soaked with a bituminous material wrapped around the steel tubes that promoted groundwater to the reservoir. This material and also the cardboard display a noticeable tar-like scent and releases PAHs contained in the soaked fabric by diffusion into the room and eventually to the outside. Table 1 comprises the content of the 16 most often quantified PAH congeners in the jute fabric. The PAH congener pattern is typical for hard coal $\operatorname{tar}^{22,23}$ with phenanthrene, fluoranthene and pyrene as most abundant congeners and with phenanthrene dominating over anthracene, benzo $[b]$ fluoranthene over benzo $[k]$ fluoranthene and indeno[1,2,3-cd] pyrene over dibenz[ah ]anthracene. The levels of naphthalene, acenaphthylene, and acenaphthene are probably largely reduced since production due to their higher volatility. The levels of airborne PAHs are influenced by complex processes including diffusion and evaporation from the partly more than 115 years old source material, and the interaction with the inorganic and organic construction materials such as concrete, brick, iron and wood, as well as the omnipresent dust particles.

Table 1 : Content of PAH congeners in the jute fabric (means and standard deviations, $n=3$ ) and respective vapor pressures at $25^{\circ} \mathrm{C}$

Therefore, in order to estimate the actual airborne PAH as basis for a risk assessment for visitors cannot be done using documented vapor pressure data for PAHs (Table 1) and diffusion models but requires measu- 
rement data. Since the building was not easily accessible during the restoration period and never meant to be accessed by visitors the technical execution of pump sampling to arrive at a PAH related risk assessment on the drip floor with the equipment described in section 2.3 was rather tedious. Thus, the situation was used to investigate if SBSE could offer an easily accessible complement to indoor risk assessment regarding harmful (semi)volatile substances. Therefore, it was firstly tested if there was any significant PAH extraction via SBSE devices and what time frame would be needed. A preliminary exposure of SBSE devices on the drip floor over up seven days revealed detectable amounts of all 16 PAH congeners already after one day of exposure. This encouraged two SBSE sampling campaigns, each displaying exposure periods of one day intervals up to five or seven days, respectively. The campaigns were run temporally apart (July 2019 and September 2019) such that the outside temperature influence could be assessed. On each measurement day three SBSE devices were sampled to enable estimation of analytical repeatability. In addition to the sampling on the wall (Fig. 1, position S1) SBSE devices were placed along a cross section of the room (Fig. 1, position S3) in order to assess the dependence of PAH content from the distance of the source (Fig. 1, positions A2). Likewise, pump sampling followed by quantification of airborne PAH levels was performed next to the site of SBSE sampling (Fig. 1, position P) but temporally apart. Again, measurements were performed with three replicates each on different days in order to evaluate repeatability of and temperature influence on determined airborne PAH concentrations.

\subsection{Stir bar sorptive extraction}

Fig. 2 comprises the results of both SBSE sampling campaigns for selected PAH congeners. All measurement data can be found in supplementary Tables S4 and S5. On each sampling day three replicates were taken. Congeners displaying up to three rings (naphthalene to anthracene, with the exception of acenaphthylene) and pyrene are observed well above $100 \mathrm{ng}$ absolute (= ng per SBSE device) after $24 \mathrm{~h}$ while further congeners with four rings (chrysene and benzo[a $]$ anthracene) and all congeners with five rings display respective amounts below $20 \mathrm{ng}$ absolute. These significant differences in absolute masses on the SBSE devices is in accordance with the respective vapor pressures (Table 1) that are $>10^{-4} \mathrm{~Pa}$ for the three-membered ring congeners and pyrene and below $10^{-5}$ for the other investigated congeners ${ }^{24,25}$.

The repeatability of PAH determinations by SBSE as estimated from the three devices analysed for each measuring day ranges mostly between 5 and 10\% (for standard deviations see supplemental Tables S4 and S5) and is regarded satisfactory for this purpose.

Figure 2: Absolute PAH content on SBSE devices after different exposition times (wall; see Fig. 1, position $\mathrm{S} 1)$, means and standard deviations $(n=3) .1^{\text {st }}$ campaign: 29 July -3 August; $2^{\text {nd }}$ campaign: $23-30$ September.

While during the first campaign sorbed naphthalene and acenaphthylene levels did not change significantly after the first $24 \mathrm{~h}$ the levels of the other depicted congeners increased over the sampled period. This effect tended to increase with molecular weight from acenaphthene to pyrene while on the last day the amount of these higher molecular weight congeners dropped significantly. In contrast to this, the second campaign displayed this increasing tendency without the decrease of the higher molecular weight congeners but here an initial increase of the naphthalene content between day 1 and day 2 was followed by significant decrease on the last three days. This behavior cannot be comprehensively explained only on basis of the temperature courses during the campaigns. During the first campaign the room temperature dropped from $25^{\circ} \mathrm{C}$ on the first day to $20{ }^{\circ} \mathrm{C}$ on the last day, while in the second campaign started at $16{ }^{\circ} \mathrm{C}$ and ended at $14{ }^{\circ} \mathrm{C}$. For a tentative reasoning it should be noted that naphthalene is transported to a significant degree in the gas phase while the other congeners display a tendency increasing with molecular weight to be transported bound to particles $^{26}$.

It appears that influence factors with opposite effect affected the absolute amount and pattern of PAH congeners on the SBSE devices. While in the first campaign sorption of higher molecular weight congeners tended to accelerate in the first days the decrease on the last day is best explained with strong air exchange on the last, coolest day of the campaign. This loss tended to increase with increasing molecular weight 
and decreasing vapor pressure and is consistent with the concept of a blow-off - possibly by a gust-like event - that partly removed particles from the SBSE devices. As a consequence, the absolute amount of predominantly particle bound congeners (e.g. fluoranthene and pyrene) would be reduced while congeners displaying a significant vaporisation and thus a largely constant airborne concentration would be less affect as observed in case of naphthalene and acenaphthene.

In the second campaign with cooler temperatures nearly all congener contents increased over the days, those with lower vapor pressure initially slower than in first campaign. Naphthalene stands out though its content also increased on the devices in the first days consistent with cooler temperatures that might have affected the desorption from the source and the diffusion through the room. The content decrease observed only for naphthalene in the last days of the second campaign cannot be explained with any certainty on basis of the available information. It might be due to re-volatilisation as a consequence of air exchange and cooler temperature resulting in less desorption from the source that decreased the naphthalene air concentration without in this case significantly affecting the particles bound to the devices.

Fig. 3 shows that the PAH distribution did not differ significantly across the room between source and wall (Fig. 1, positions S3). For measurement data in detail see supplementary Table S6. This observation is supported by the results obtained from SBSE devices that were placed close to the PAH source (Fig. 1, position S2) during both campaigns. The three devices each were sampled after $24 \mathrm{~h}$ in the first campaign and after $48 \mathrm{~h}$ in the second campaign. The results depicted in detail in supplementary Figure S1 and supplementary tables S4 and S5 reveal no significant differences of sampled PAH congener masses at positions S1 and S2 (Fig. 1).

Figure 3: Absolute PAH content on SBSE devices exposed for $24 \mathrm{~h}$ (11 - 12 September) on the floor with different distances from the PAH source (see Fig. 1, position S3), means and standard deviations ( $\mathrm{n}=3$ ).

\subsection{Pump sampling}

The experiments on the recovery rates of PAH congeners from the PU foam sampling devices in the pump sampling procedure were throughout above $90 \%$ (supplementary Table S2). The average respiratory volume of a person at rest is about $750 \mathrm{~L} \mathrm{~h}^{-1}$ and may reach $1 \mathrm{~m}^{3} \mathrm{~h}^{-1}$ after light exercise such as climbing a staircase. Based on the idea that a visitor would stay on the premises for less than one hour air was sampled for one hour for each determination of airborne PAHs. Fig. 4 comprises the results of pump sampling on the drip floor. PAH concentrations are given separately for the PU foams and the respective quartz filters. The standard deviations of the triplicate determinations are generally below $20 \%$ and may reach $50 \%$ in cases where airborne congener concentration were below $5 \mathrm{ng} \mathrm{m}^{-3}$. In exceptional cases the very low concentrations sampled on quartz filter may display standard deviation up to $100 \%$. There is no obvious difference between intraday and interday repeatabilities and they are reasonably small to allow assessment of airborne PAH concentrations and the influence of temperature. The complete set of data separately for PU foams and quartz filters are collected in supplementary Tables S7 and S8.

Figure 4: PAH concentrations in air determined after pump sampling at the wall (see Fig. 1, position P) in PU foams and quartz filters, means and standard deviations $(n=3)$. Intraday 1: 29 July; intraday 2: 11 September; interday: 30 July - 1 August.

As for the stir bar sorptive extraction the pattern of relative congener abundance is biased towards the congeners with lower molecular weight and higher vapor pressures when compared with the congener pattern of the source (Table 1). Supplementary Figure S2 juxtaposes the PAH congener patterns in the source, on the SBSE devices, on the PU foams and on the quartz filters.

The three pump sampling sequences (intraday 1 and 2, interday) reveal the expected dependence of airborne PAH content on the room temperature $\left(20{ }^{\circ} \mathrm{C}, 15{ }^{\circ} \mathrm{C}, 19-20{ }^{\circ} \mathrm{C}\right)$. The observation of highest naphthalene abundance on the quartz filter on the coolest sampling day (interday 2) may be attributed to the temperature susceptibility of the vapor pressure of this congener. With increasing temperature, naphthalene bound to the particles captured on the quartz filter should be blown into the PU foam by the constant pump flow. 
This effect is likely to occur in case of all PAH congeners though it should decrease with vapor pressure of the respective congener. However, there are obviously significantly different affinities among PAH congeners towards particles independent from the respective vapor pressure as may be concluded from the high abundance of acenaphthene on the quartz filter that exceed as sole congener even that in the PU foam.

\subsection{Comparison of pump sampling and stir bar sorptive extraction}

Because the amount of PAHs extracted with a given SBSE device from the indoor air cannot be assigned to a specific air volume in contrast to pump sampling where the analyte content is filtered out from a defined volume there is no directly obvious correlation between both approaches.

SBSE is far from reaching saturation in the time scale of several days but obviously exhibits detectable adsorption of each PAH congener already within one day. The course of further adsorption over consecutive days is obviously congener-specific and subjected to a continuous sorption/desorption dynamic triggered by temperature and air exchange. In contrast, pump sampling is unaffected by moderate air exchange due to the short sampling period and desorption of compounds once sampled on the filter is completely excluded.

Nevertheless, both sampling principles display largely similar congener patterns which means that SBSE does not discriminate between PAH congeners significantly different than pump sampling and can be regarded as equivalent in this regard. Both principles are expectedly influenced by temperature as this triggers the desorption of PAHs from the source in the first place.

It is seen that absolute absorbed masses on a SBSE device after one day in the first campaign ranged between 40 - $100 \mathrm{ng}$ in case of acenaphthylene and anthracene, between 100 and $600 \mathrm{ng}$ in case of naphthalene, acenaphthene, fluorene and pyrene, between 1000 and $2000 \mathrm{ng}$ in case of phenanthrene and fluoranthene as the most abundant congeners, and up to $15 \mathrm{ng}$ in case of benzo[ $a$ ]pyrene and the other 4 and 5 membered ring congeners (Fig. 2 and supplementary Table S4).

In comparison to that pump sampling revealed airborne concentrations in the warmer weather samplings (intraday 1 and interday, Fig. 3 and Tables S7 and S8) up to about $100 \mathrm{ng} \mathrm{m}^{-3}$ in case of naphthalene, acenaphthene, fluorene and pyrene, up to between 250 and $800 \mathrm{ng} \mathrm{m}^{-3}$ in case of phenanthrene and fluoranthene and up to about $2 \mathrm{ng} \mathrm{m}^{-3}$ in case of the other 4 and 5 membered ring congeners. Both sampling concepts revealed lower concentrations or absolte amounts in case of cooler weather $\left(2^{\text {nd }}\right.$ SBSE campaign and intraday 2). This information on absolute PAH level sampled by SBSE in comparison to pump sampling should be sufficient to decide on the necessity of pump sampling providing a mass per volume estimate of $\mathrm{PAH}$ contamination. In addition, the dynamics of SBSE may be explored over a period of time and range of conditions to select pump sampling conditions regarded as most appropriate. It should be noted that in settings with less or controlled air exchange an even better correlation between both sampling approaches may be observed.

\section{Conclusions}

The application of SBSE devices allows a rapid and low-cost assessment of airborne PAHs levels in indoor environments and may help to decide if more sophisticated standardized sampling procedure are worth being applied. The charm of this approach lies the easy applicability and the option to investigate a given architecture in space and time and thus not only estimate airborne levels but provide valuable information on the dynamics of analyte interaction between sources and sinks and the influence of temperature and aeration. Since PAH congener pattern observed after stir bar sorptive extraction from indoor air resembled largely that observed after pump sampling it should serve as orientating procedure to assess necessity for pump sampling. Future developments may use different SBSE device sizes, different adsorber phases and modified placement of SBSE devices such that adsorption of dust particles can optionally be allowed or excluded in a controlled manner. Thus, SBSE may be developed towards a procedure suppoorting a comprehensive risk assessment regarding PAH levels in indoor environments.

\section{Conflict of interest}


Authors have no conflict of interest relevant to this article

\section{Acknowledgements}

Authors are indebted to VERMDOK GmbH, Berlin, Germany, for provision of the image used in Fig. 1 and to Dampflokfreunde Berlin e. V. for the opportunity to conduct sampling in the historic water tower.

\section{References}

1. Naphthalene indoor limit values in Germany: https://www.eggbi.eu/forschung-undlehre/zudiesemthema/naphthalin/ (accessed: 27 October 2020)

2. Benzo[a]pyrene indoor limit values in Germany: https://www.lfu.bayern.de/analytik_stoffe/doc/infoblatt_benzoapyren.pdf (accessed: 27 October 2020)

3. Liu LB, Lin JM, Tang N, Hayakawa K, Maeda T. Development of analytical methods for polycyclic aromatic hydrocarbons (PAHs) in airborne particulates: A review. J Env Sci 2007;19:1-11.

4. DIN EN ISO 16000-12 Indoor air: Sampling strategy for polychlorinated biphenyls (PCBs), polychlorinated dibenzo-p-dioxins (PCDDs), polychlorinated dibenzofurans (PCDFs) and polycyclic aromatic hydrocarbons (PAHs)

5. David F, Ochiai N, Sandra P. Two decades of stir bar sorptive extraction: A retrospective and future outlook. TRAC-Trend Anal Chem 2019;112:102-111.

6. Matsiko J, Li H, Wang P, Sun H, Zheng S, Wang D, Zhang W, Hao Y, Li Y, Zhang Q, Jiang G. Stir bar sorptive extraction and thermal desorption - gas chromatography/mass spectrometry for determining phosphorus flame retardants in air samples. Anal Methods 2018;10:1918-1927.

7. Cacho JJ, Campillo N, Vinas P, Hernandez-Cordoba M. Evaluation of three headspace sorptive extraction coatings for the determination of volatile terpenes in honey using gas chromatography-mass-spectrometry. J Chromatogr A 2015;1399:18-24.

8. Lee J, Shibamoto T, Ha J, Jang HW. Identification of volatile markers for the detection of adulterants in red ginseng (Panax ginseng) juice using headspace stir-bar sorptive extraction coupled with gas chromatography and mass spectrometry. J Sep Sci 2018;41:2903-2912.

9. Cacho JJ, Campillo N, Alsite M, Vinas P, Hernandez-Cordoba M. Headspace sorptive extraction for the detection of combustion accelerants in fire debris. Forensic Sci Int 2014;238:26-32.

10. Gallidabino M, Romolo FS, Weyermann C. Time since discharge of $9 \mathrm{~mm}$ cartridges by headspace analysis, part 1: Comprehensive optimisation and validation of a headspace sorptive extraction (HSSE) method. Forensic Sci Int 2017;272:159-170.

11. Kolahgar B, Hoffmann A, Heiden AC. Application of stir bar sorptive extraction to the determination of polycyclic aromatic hydrocarbons in aqueous samples. J. Chromatogr A 2002;963:225-230.

12. Niehus B, Popp P, Bauer C, Peklo G, Zwanziger HW. Comparison of stir bar sorptive extraction and solid phase extraction as enrichment techniques in combination with column liquid chromatography for the determination of polycyclic aromatic hydrocarbons in water samples. Int J Env Anal Chem 2002;82:669-676.

13. Garcia-Falcon MS, Cancho-Grande B, Simal-Gandara J. Stirring bar sorptive extraction in the determination of PAHs in drinking waters. Water Res 2004;38:1679-1684.

14. Roy G, Vuillemin R, Guyomarch J. On-site determination of polynuclear aromatic hydrocarbons in seawater by stir bar sorptive extraction (SBSE) and thermal desorption GC-MS. Talanta 2005;66:540-546.

15. Krueger O, Christoph G, Kalbe U, Berger W. Comparison of stir bar sorptive extraction (SBSE) and liquid-liquid extraction (LLE) for the analysis of polycyclic aromatic hydrocarbons (PAH) in complex aqueous matrices. Talanta 2011;85:1428-1434. 
16. Barco-Bonilla N, Romero-Gonzalez R, Plaza-Bolanos P, Fernandez-Moreno JL, Frenich AG, Vidal JLM. Comprehensive analysis of polycyclic aromatic hydrocarbons in wastewater using stir bar sorptive extraction and gas chromatography coupled to tandem mass spectrometry. Anal Chim Acta 2011;693:62-71.

17. Krueger O, Olberg S, Senz R, Simon FG. Comparison of Stir Bar Sorptive Extraction (SBSE) and Solid Phase Microextraction (SPME) for the Analysis of Polycyclic Aromatic Hydrocarbons (PAH) in Complex Aqueous Soil Leachates. Water Air Soil Poll 2015;226:397.

18. Foan L, Ricoul F, Vignoud S. A novel microfluidic device for fast extraction of polycyclic aromatic hydrocarbons (PAHs) from environmental waters - comparison with stir-bar sorptive extraction (SBSE). Int J Env Anal Chem 2015;95:1171-1185.

19. Li XM, Zhang QH, Wang P, Li YM, Jiang GB. Determination of Polycyclic Aromatic Hydrocarbons in Air by Stir Bar Sorptive Extraction-Thermal Desorption-Gas Chromatography Tandem Mass Spectrometry. Chin J Anal Chem, 2011;39:1641-1646.

20. ISO 11843-2:2000-05 - Capability of detection - Part 2: Methodology in the linear calibration case.

21. DINTEST: University of Heidelberg, Germany, 2001.

22. Certified reference material BAM-U013c - Polycyclic aromatic hydrocarbons in soil, (2018). https://www.webshop.bam.de/show_blob_data.php?filename=pdf\%2Fcertificates\%2Fbam_u013c_e.pdf (accessed: 28.10 .2020$)$

23. Valentyne A, Crawford K, Cook T, Mathewson PD. Polycyclic aromatic hydrocarbon contamination and source profiling in watersheds serving three small Wisconsin, USA cities. Sci tot Env 2018;627:1453-1463.

24. Achten C, Andersson JT. Overview of Polycyclic Aromatic Compounds (PAC). Polycycl Aromat Comp 2015;35:177-186.

25. WHO (World Health Organisation): Selected non-heterocyclic polycyclic aromatic hydrocarbons. IPCS-Environmental Health Criteria 202, WHO, Genf, CH, 1998. http://www.inchem.org/documents/ehc/ehc/ehc202.htm\#SectionNumber:1.2 (accessed: 28.10.2020)

26. Harrison RM, Smith DJT, Luhana L. Source Apportionment of Atmospheric Polycyclic Aromatic Hydrocarbons Collected from an Urban Location in Birmingham, U.K. Environ Sci Technol 1996;30:825-832.

Table 1: Content of PAH congeners in the jute fabric (means and standard deviations, $n=3$ ) and respective vapor pressures at $25{ }^{\circ} \mathrm{C}$

\begin{tabular}{lll}
\hline PAH congener & Content $\left(\mathrm{mg} \mathrm{kg}^{-1}\right)$ & Vapor pressure $^{+}(\mathrm{Pa})$ \\
\hline Naphthalene & $66 \pm 29$ & $1.13 \times 10^{-1}$ \\
Acenaphthylene & $45.2 \pm 2.5$ & $8.90 \times 10^{-1}$ \\
Acenaphthene & $25.1 \pm 0.5$ & $2.87 \times 10^{-1}$ \\
Fluorene & $193 \pm 35$ & $8.00 \times 10^{-2}$ \\
Phenanthrene & $3508 \pm 511$ & $1.61 \times 10^{-2}$ \\
Antracene & $1282 \pm 142$ & $1.07 \times 10^{-3}$ \\
Fluoranthene & $3395 \pm 376$ & $1.23 \times-10^{-3}$ \\
Pyrene & $3905 \pm 372$ & $6.00 \times 10^{-4}$ \\
Benz[a]anthracene & $1851 \pm 260$ & $2.80 \times 10^{-5}$ \\
Chrysene & $2441 \pm 368$ & $8.30 \times-10^{-7}$ \\
Benzo[b]fluoranthene & $1062 \pm 238$ & $6.67 \times-10^{-5}$ \\
Benzo[k]fluoranthene & $525 \pm 64$ & $1.05 \times-10^{-7}$ \\
Benzo[a]pyrene & $1466 \pm 259$ & $7.3 \times 10^{-7}$ \\
Dibenz[ah]anthracene & $189 \pm 25$ & $1.33 \times-10^{-8}$ \\
Indeno(1,2,3- $c d]$ pyrene & $740 \pm 146$ & $1.67 \times-10^{-8}$
\end{tabular}




\begin{tabular}{lll}
\hline PAH congener & Content $\left(\mathrm{mg} \mathrm{kg}^{-1}\right)$ & Vapor pressure $^{+}(\mathrm{Pa})$ \\
\hline Benzo $[$ ghi $]$ perylene & $791 \pm 158$ & $1.33 \times-10^{-8}$ \\
\hline
\end{tabular}

+ vapor pressure data taken from ref. 24 , in case of in case of benzo[ $a$ ]pyrene from ref. 25

Figure captions:

Figure 1: Layout of the third floor, PAH sources and sampling spots.

Figure 2: Absolute PAH content on SBSE devices after different exposition times (wall; see Fig. 1, position $\mathrm{S} 1)$, means and standard deviations $(\mathrm{n}=3)$. $1^{\text {st }}$ campaign: 29 July -3 August; $2^{\text {nd }}$ campaign: $23-30$ September.

Figure 3: Absolute PAH content on SBSE devices exposed for $24 \mathrm{~h}$ (11 - 12 September) on the floor with different distances from the PAH source (see Fig. 1, position S3), means and standard deviations ( $\mathrm{n}=3$ ).

Figure 4: PAH concentrations in air determined after pump sampling at the wall (see Fig. 1, position P) in PU foams and quartz filters, means and standard deviations $(n=3)$. Intraday 1: 29 July; intraday 2: 11 September; interday: 30 July - 1 August. 

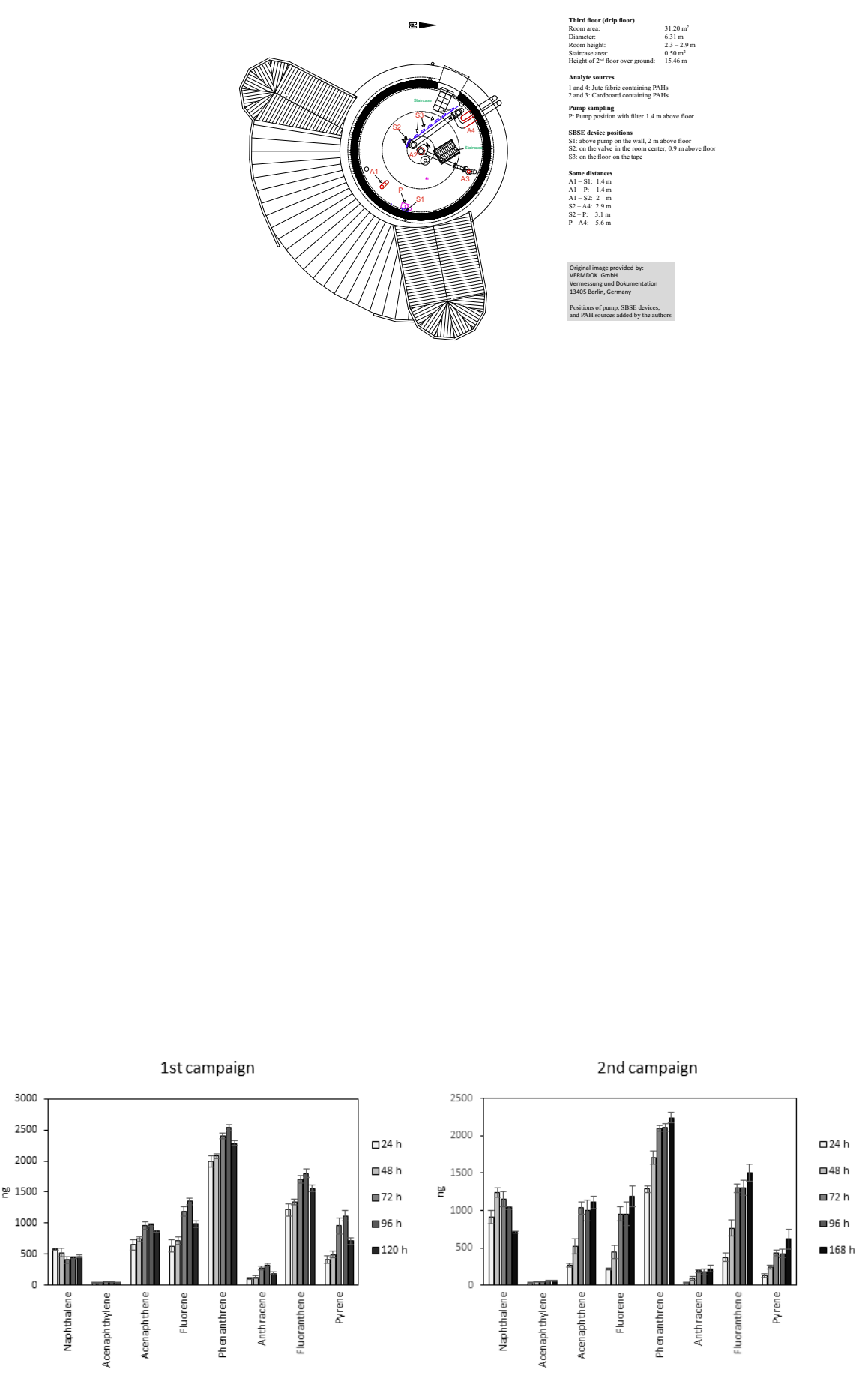

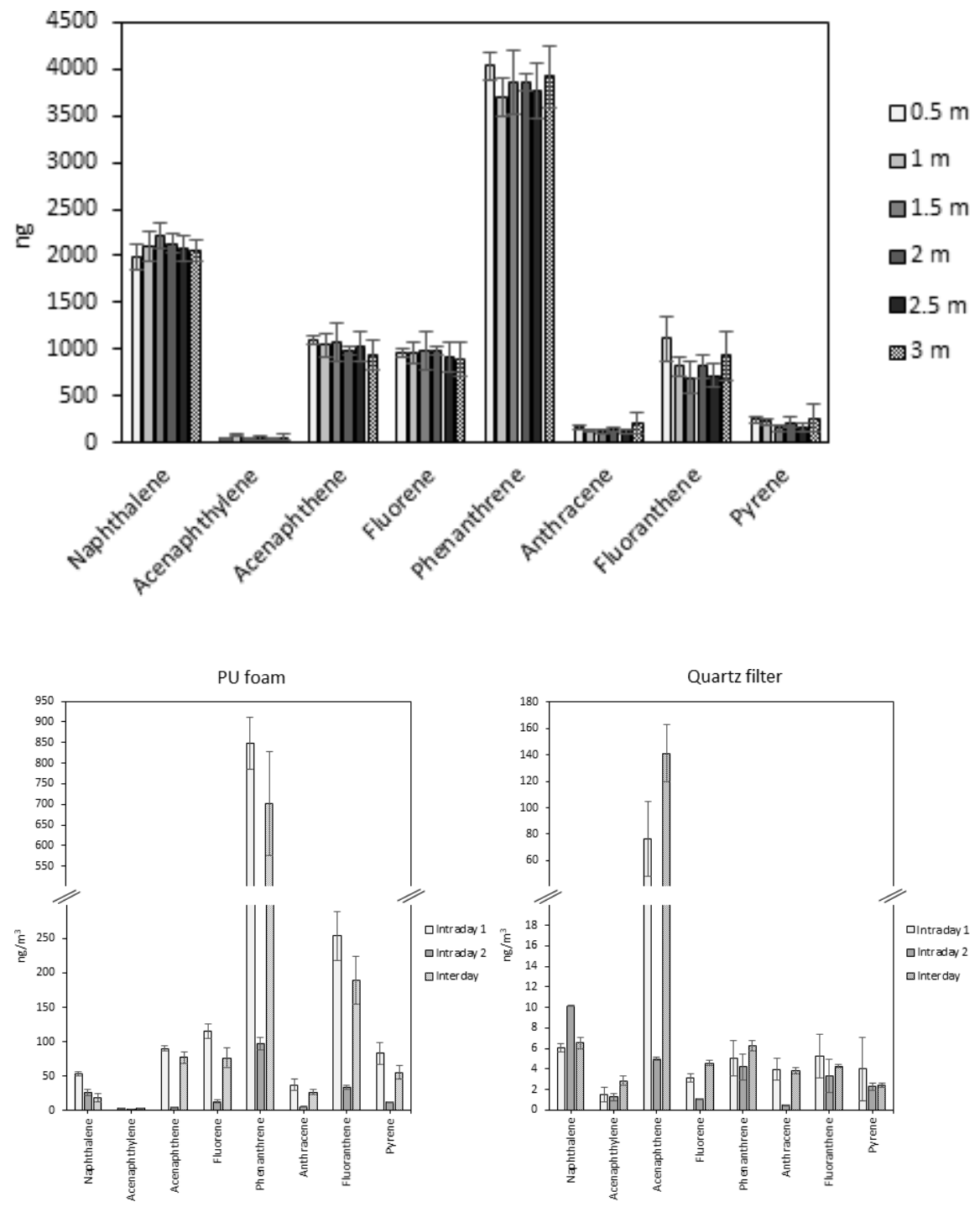